\title{
DYNAMIC ANALYTIC NETWORK PROCESS: IMPROVING DECISION SUPPORT FOR INFORMATION AND COMMUNICATION TECHNOLOGY
}

\author{
Tom Feglar ${ }^{1}$, Jason K. Levy ${ }^{2}$ \\ 1 Enterprise Architect, Prague, Czech Republic, feglar@centrum.cz \\ 2 University of Hawaii, Information and Computer Science Department, Pearl Citv.HI. USA. 97782, \\ jlevy@hawaii.edu
}

Keywords: AHP, ANP, Dynamic ANP, BUSINESS Rules Motivation Model, Architecture Framework, ICT Innovation

Summary: Information and Communication Technology (ICT) becomes very important driven force that could have significant impact to the enterprise. It cannot be ignored thanks to competition. Massive ICT innovation could be too risky thanks unpredictable and complex impact. We focus our attention to the classification of various ICT based innovations that will allow us development of AHP/ANP/DNP class of models suitable for ICT driven innovation management.

AHP/ANP/DNP methods are very powerful. At the same time it is difficult - especially in complex problems - design of appropriate hierarchical structure (AHP), the control structure (ANP) and decision horizon (DNP). Application of these methods to the ICT driven decisions could be significantly simplified if we integrate decision models to the enterprise architecture framework.

In our paper we describe a set of classification criteria (derived from enterprise architecture perspective) and apply them to the classification of various papers dealing with ICT based innovation

\section{Introduction}

AHP, ANP and Dynamic ANP methods were successfully applied in various decision making situations that have many similar features with decisions activated by ICT innovations; some of them are mentioned here:

- Development of AHP model for the designing and manufacturing of a competitive technical solution [4]

- $\quad$ Design of a Hierarchy for Dynamic Evaluation [13]

- $\quad$ Prioritizing Enterprise Resource Planning Software [7]

- $\quad$ Effect Evaluation on Enforcing information quality of knowledge management [9]

- $\quad$ AHP/ANP Usage for a Cooperation between IT Architect and Decision Maker [5]

- $\quad$ Using the Analytic Hierarchy Process for radioactive waste management [8]

- $\quad$ Modeling of comparative assessment of open source products [10]

Significant contributions to highly successful AHP/ANP/Dynamic ANP methods based solutions have two software packages -and Super Decisions and Expert Choice. Last one has been tested and compared with four other MCDM software packages (HiView, VISA, Web-Hipre and Logical Decisions [6].

As a result of this comparison two general areas of improvement were identified for all five packages:

a) Problem formulation and structuring

While Expert Choice does provide support for brainstorming a list of entities for the analysis and then building the model, none of the packages really draw upon the growing range of problem formulation methodologies. By other words, all packages provide excellent support for decision analytic calculations but little in the way of support of the decision making process itself, especially in the areas of decision contexts development and subsequent decision model structure derivation. 
b) Sensitivity analysis enhancement

None of the packages explores the full range of sensitivity analysis that is possible. Perhaps all packages could move in these directions - the most perspective feature seems to be identification of potentially optimal alternatives (in dependency on context).

\section{Architect's Responsibility to Harmonize Business Needs with the ICT Power}

A complexity of current ICT rapidly increases and becomes less and less understandable for business owners. To compensate the risks dealing with a gap between business processes and their dependencies on ICT functionalities enterprise architect's mechanism becomes more and more important. This mechanism assists (Figure 1):

- In a transformation of user's (business owner's) specified behavior into architect's specified behavior

- Decision makers in synthesizing a decision support models solving problems of the most optimal balancing between architecture specified behavior and ICT driven innovation functionalities.

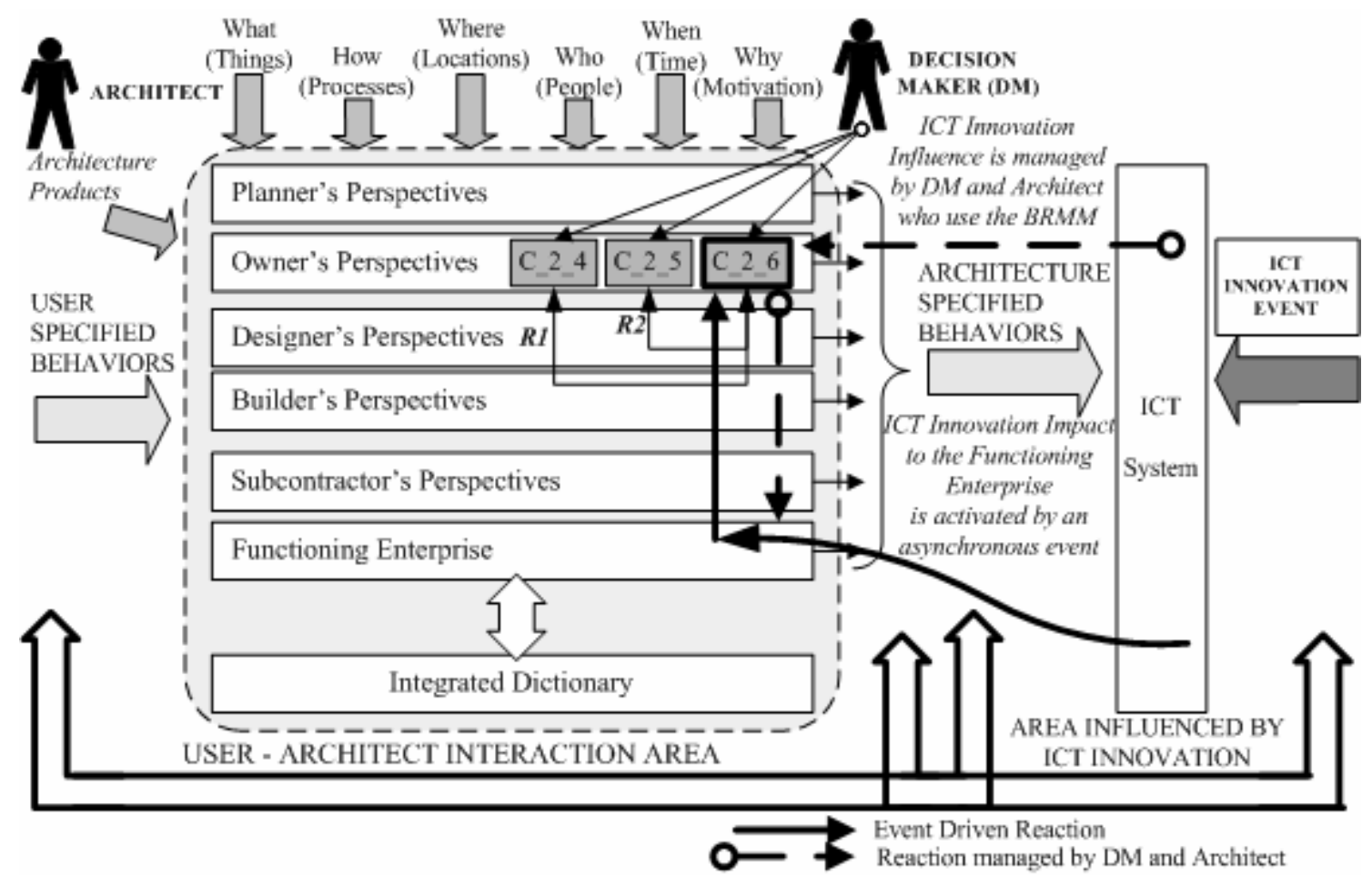

Figure 1 Architecture framework allows effective cooperation between Architect and Decision Maker

To fulfill his mission architect must develop a set of architecture products within reference architecture framework. Figure 1 depicts Zachman framework combining perspectives (rows) and aspects (columns). Using this framework we can easily identify a common cooperation area between architect and decision maker; this area consists of three cells:

- $\quad$ The cell C 2 6 that captures Business Rule Motivation Model (BRMM) that includes business strategies, tactics, policies and rules

- $\quad$ The cell C 2 _ 5 that captures transition diagram starting with “As-Is" through "Next-Step” to the "Should Be" statuses

- $\quad$ The cell C_2_4 that captures organization chart describing all organization items participating in business strategies and tactics realizations,

and relationships among these three cells - R1 and R2:

- $\quad$ The relationship R1 describes connections between BRMM and people who carry responsibilities for various BRMM items 
- $\quad$ The relationship R2 describes connections between BRMM and time that is necessary to achieve strategic goals and tactical objectives.

At the bottom part of the figure 1 you can see two areas:

- $\quad$ User - Architect Interaction Area covers a transformation of user specific behaviors onto architecture specified behaviors

- $\quad$ Area influenced by ICT innovation modifies architecture specified behavior. Modification process is activated asynchronously from user specification by events that are usually out of the enterprise framework.

Figure 1 illustrates two kinds of reactions to the ICT Innovation Event.

Event Driven (ED) reaction impacts Functioning Enterprise; these impacts are registered primarily by subcontractors or builders. ED activated change management stimulates "bottom- up wave" that finally reaches owner's perspective and activates decision making situation.

Reaction managed by DM and Architect starts with preliminary activities dealing with BRMM customization in accordance with decision context that corresponds to the ICT Innovation event. These preliminary activities stimulate "top-down wave” that firstly influence designer's perspective, and then other lower perspectives.

It is clear that only ICT innovation reaction managed by DM and Architect allows enterprise surviving in a competitive world. It must become a integral part of strategic and tactical levels of decisions.

Next two sections explain relationships decision context, decision process concept and their relationships to the BRMM.

\section{Decision Contexts and Decision Processes Concept}

a) Decision Context

Contexts that would be considered in a decision consist of ([6]):

- $\quad$ Problem context: e.g. what are the external characteristics of the problem; is it well structured; is uncertainty present; how many options and possibilities need to be considered?

- $\quad$ Social context: e.g. what are the characteristics of the social organization in which the decision has to be made; who are the decision makers and how many are there, what are their responsibilities; who are the stakeholders?

- Cognitive factors of the DMs: e.g. how intelligent, imaginative, knowledgeable are the decision makers; can they live with risk and uncertainty; which behavioral 'biases' and 'heuristics' do they exhibit.

A lot of contexts relevant items can be developed by architect using architecture framework.

Following rules demonstrate some of these capabilities:

- A combination of cells in first three columns allow modeling a problem context,

- Cells in the column 4 are suitable primarily for social context modeling,

- Motivation cells (column 6) can effectively support cognitive factors of the DMs.

b) Decision Process Concept

Decision process concept depends on the method chosen for a decision. Next brief summary explain AHP and ANP concepts; full description of these concepts is available in [11].

b1) Concepts of the Analytic Hierarchy Process

$\mathrm{HC}$ - (Analytical) Hierarchical (Process) Concept item

HC01: Elements of the problem, goals, subgoals, scenarios, actors and stakeholders, their objectives and policies, criteria, subcriteria, attributes and alternatives. 
HC02: Hierarchic Structure

HC03: Judgments

HC04: Comparison

HC05: The number of judgments

HC06: Derived ratio scales

HC07: Interval / Stochastic judgments

HC08: Synthesis

HC09: Ranking

HC10: Absolute measurement

HC11: BOCR hierarchies

HC12: Parallel with human thinking

HC13: Group Decision making

HC14: Sensitivity Analysis

HC15: Learning and revision as a process

b2) Concepts of the Analytic Hierarchy Process

NC - (Analytical) Network (Process) Concept item

NC01: Feedback, inner and outer dependence

NC02: Influence with respect to criterion

NC03: The control hierarchy of the system

NC04: The supermatrix

NC05: The limiting supermatrix and limiting priorities

NC06: Primitivity, irreducibility, cyclicity

NC07: Making the limiting supermatrix stochastic

NC08: Synthesis for the criteria of a control hierarchy

NC09: Synthesis for BOCR control hierarchies

NC10: Formulation to compute the limit

NC11: relation to Neural Network Firing

NC12: The density of neural firing and distributions

Bolt lines show which decision process concept items could be directly influenced by a BRMM modeling.

\section{The BRMM and BOCR Enhancement}

In 1997, the Business Rules Group (BRG) published "The Standard Model for Business Rule Motivation”, known as Business Rules Motivation Model (BRMM). This model is now available as a revision 1.0 (year 2000) [15]. There are two major areas of the original BRMM developed by the BR group (see left site in the Figure 2 [15]):

- The first is the End and Means of business plans. Among the End are things the enterprise wishes to achieve - for example, Goals and Objectives. Among the Means are things the enterprise will employ to achieve those Ends - for example Strategies and Tactics.

- The second is the Influence that is recognized by an Organization Unit. This unit makes SWOT assessment, that also includes a judgments about influences.

It is worth mention next few relationships among BRMM functional modules:

- Strategy and Tactic (Course of Action) relate to the Goal and Objective (Desired Results)

- SWOT Assessment:

- Expresses the impact of influences on the End (Vision, Goal, Objective)

- Expresses the impact of influences on the Means (Mission, Course of Action, Element of Guidance)

- Is made by Organization Unit

- Concerns of a judgment about influence 


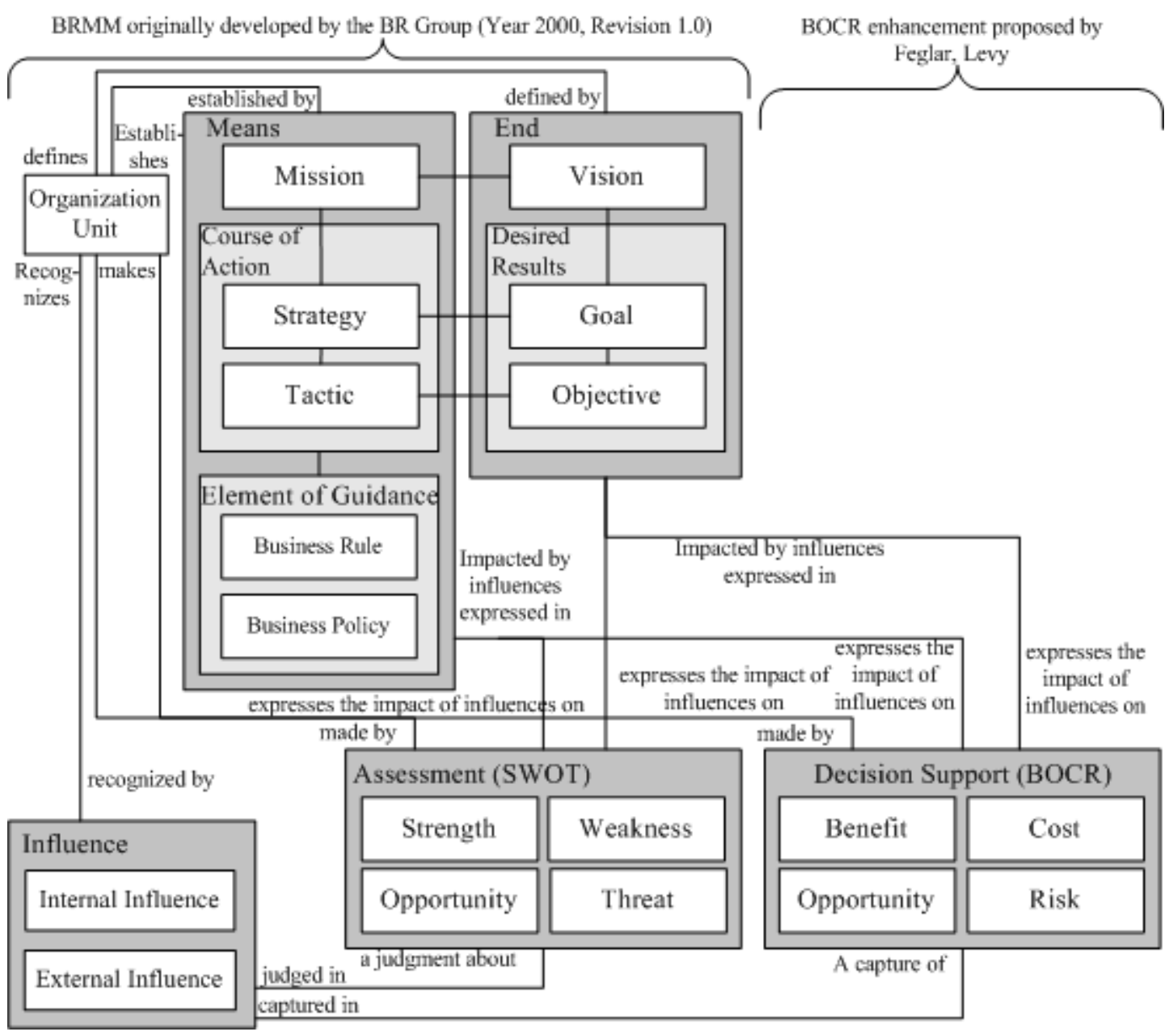

Figure 2 Business Rules Motivation Model (BRMM) and BOCR Enhancement

Right part of the Figure 2 depicts a BOCR enhancement that is not a part of the originally proposed BRMM. Missing, explicitly defined decision support model creates a potential inconsistency in the system life cycle history. From long term perspective it is very important to store all decision situations in the past and all about decisions already made. BOCR enhancement let accumulation of all these decision relevant knowledge.

As was mentioned above we use AHP / ANP methods for synthesizing BOCR models. BRMM basement can be very effectively used for overcoming difficulties with criteria identification and structuring (similar problem occur in case of control hierarchy of the system when we use ANP).

\section{The BRMM and The Control Hierarchy of the System}

BRMM Influence part directly influences an ANP Control Hierarchy, particularly control hierarchies under each subcriterion or objective (Figure 3).

There are two types of control criteria (sub-criteria)[12]. A control criterion may be directly connected to the structure as the goal of a hierarchy if the structure is in fact a hierarchy. In this case the control criterion is called a comparison - "linking" criterion. Otherwise a control criterion does not connect directly to the structure but "induces" comparisons in a network. In that case the control criterion is called a comparison - "inducing" criterion.

ANP based Decision Support module combines comparison - "linking" and comparison - "inducing" criteria by the following way (Figure 3): 
- BRMM End part (Desired Results) and Means part (Course of Action) link strategic goals with control criteria - tactical objectives,

- BRMM Influence module (including External and Internal Influences) induces sub-criteria and a possible different network under each sub-criterion using external and internal influences.

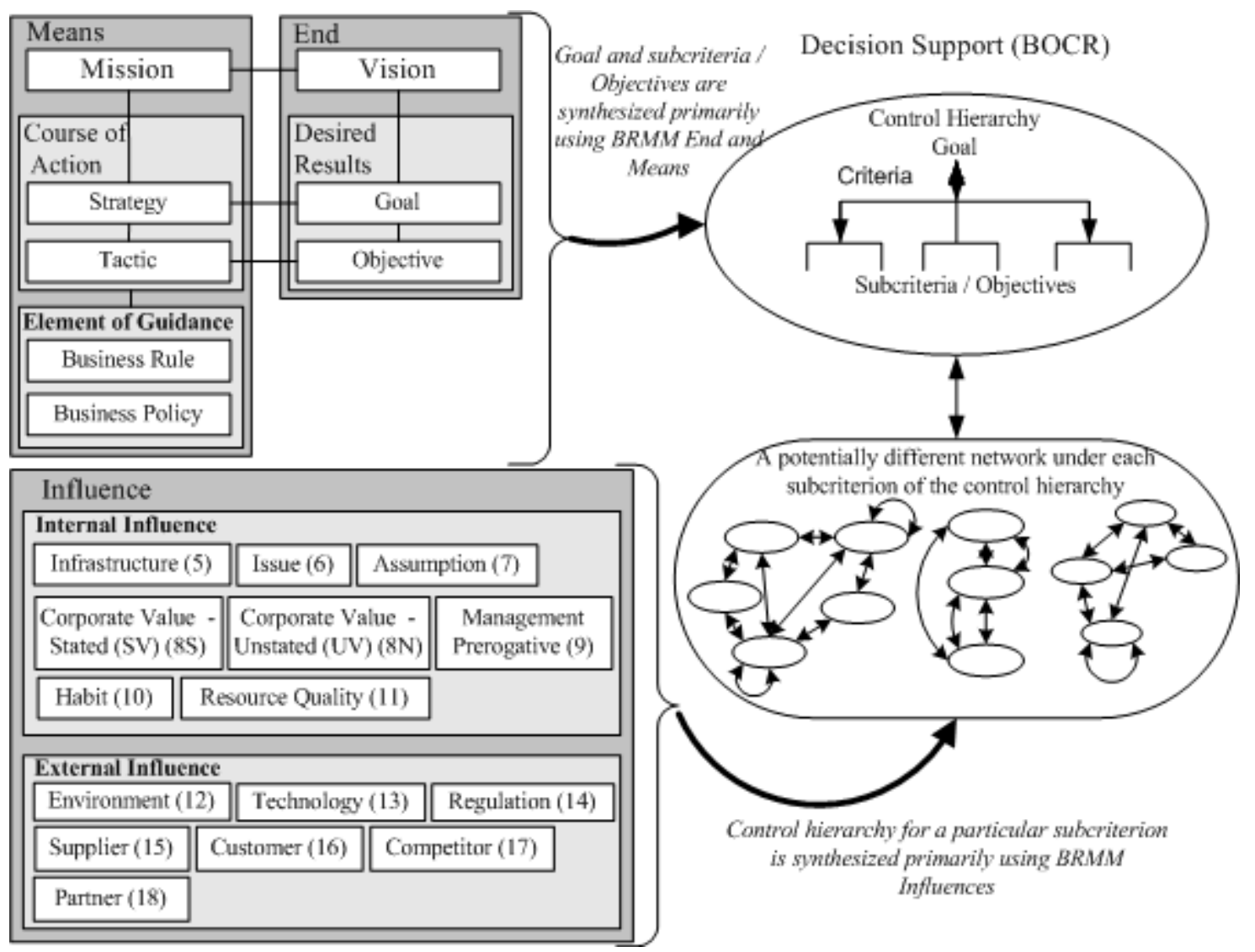

Figure 3 BRMM Usage for ANP Control Hierarchy synthesis

\section{The BRMM and Alternatives}

Integral parts of decision models are alternatives. Problem with alternatives in complex systems deals with dynamic changes in a time frame. ICT innovations can influence a broad range of time frames. Figure 4 depicts example of <AS-IS, NEXT STEP, SHOULD BE> Time Frame that offers powerful mechanism for merging Dynamic ANP with explicit life history concept.

Each part of the Time Frame (AS-IS, NEXT STEP, and SHOLUD BE) includes two components Dynamic ANP Customization and Decision Making. Alternatives that are encapsulated within Decision Making component correspond to Course of Action. It allows application of dynamic ANP approach in accordance with [13].

Upper part of the Figure 4 describes two independent entities - Organization Unit and ICT Sub-system and two dependent entities - Mission and Vision. Diagram also depicts relationships among independent and dependent entities.

Entity Risks is also independent entity that influences both - Organization unit and ICT Sub-system. This entity becomes a mandatory part of BOCR modeling. 


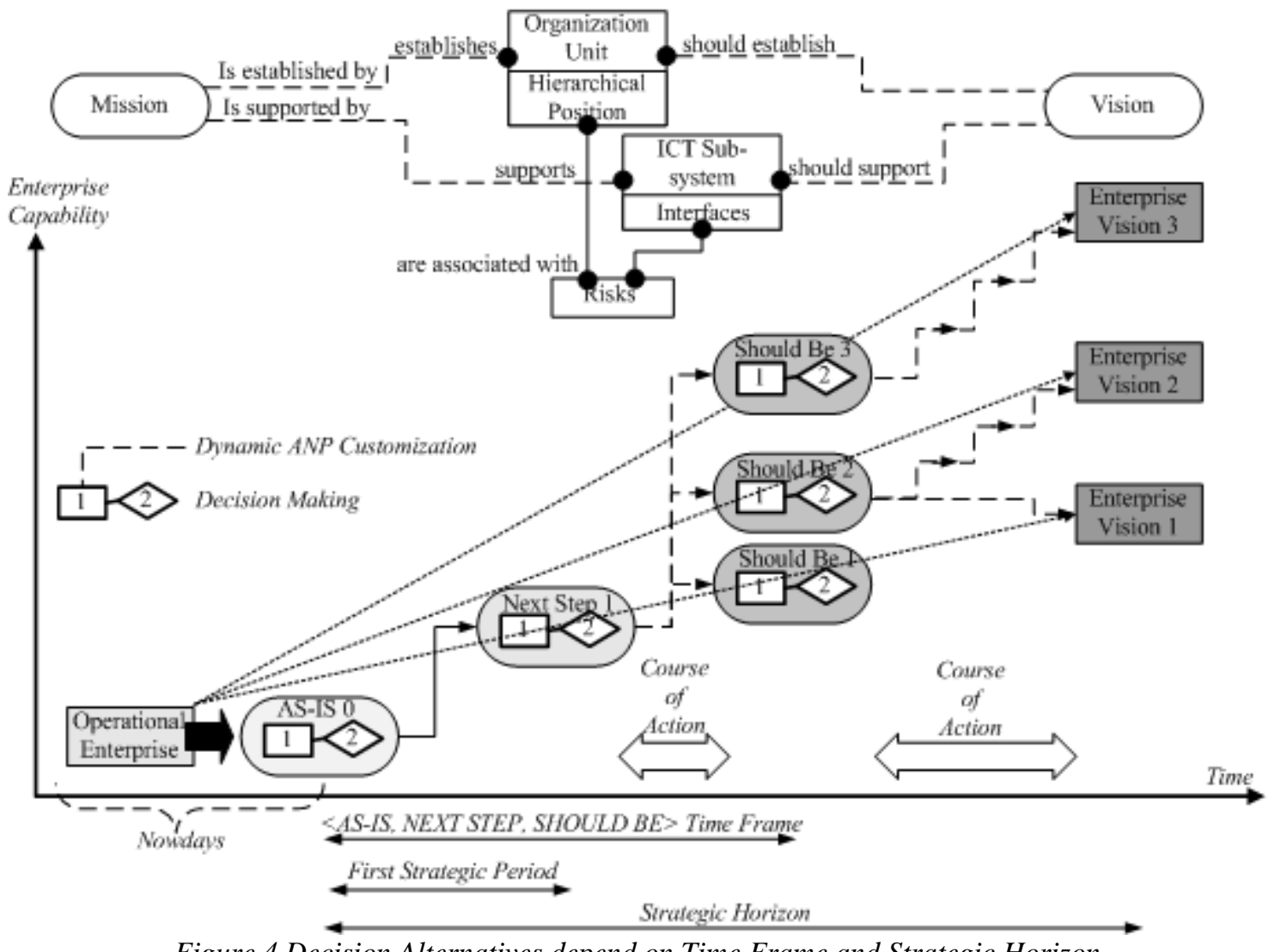

Figure 4 Decision Alternatives depend on Time Frame and Strategic Horizon

\section{The BRMM Components and Document Classification}

Application of the BRMM for a Dynamic ANP control hierarchy and alternatives synthesis has significant positive impact to the replicable application of a decision model again and again. Differences among particular applications can be successfully solved as a customization task that is much simpler and cheaper then full decision model synthesis.

This section dives more deeply into the content of particular clusters of network elements, their dependencies within a cluster and also include inter - cluster dependencies.

Decision Maker and his supporting team have completed a lot of analytical resources before he starts with new complex system. Significant part of analytically valuable information is encapsulated within documents, as for example conference papers. Appropriate classification of these documents in accordance with classification system can give us additional value; the problem is what classification system would be applied. Classical classification systems that are used in libraries are not suitable and searching documents on the base of occasionally chosen key words is time consuming task.

Figure 5 shows our idea to use BRMM as a basement for classification system. Particular BRMM items are considered as classification "attributes".

Attributes are split into six parts:

1 - Attribute used as unique identifier of a document

Attributes $\{2-4\}$ correspond to BRMM End and Means

Attributes $\{5-11\}$ correspond to BRMM Internal Influence

Attributes $\{12-18\}$ correspond to BRMM External Influence

Attributes $\{19,20\}$ correspond to BRMM Organization and Risk entities

Attributes $\{21,22\}$ are beyond the scope of the BRMM and allow identification of document that explicitly mentions decision making and / or AHP/ANP methods. 


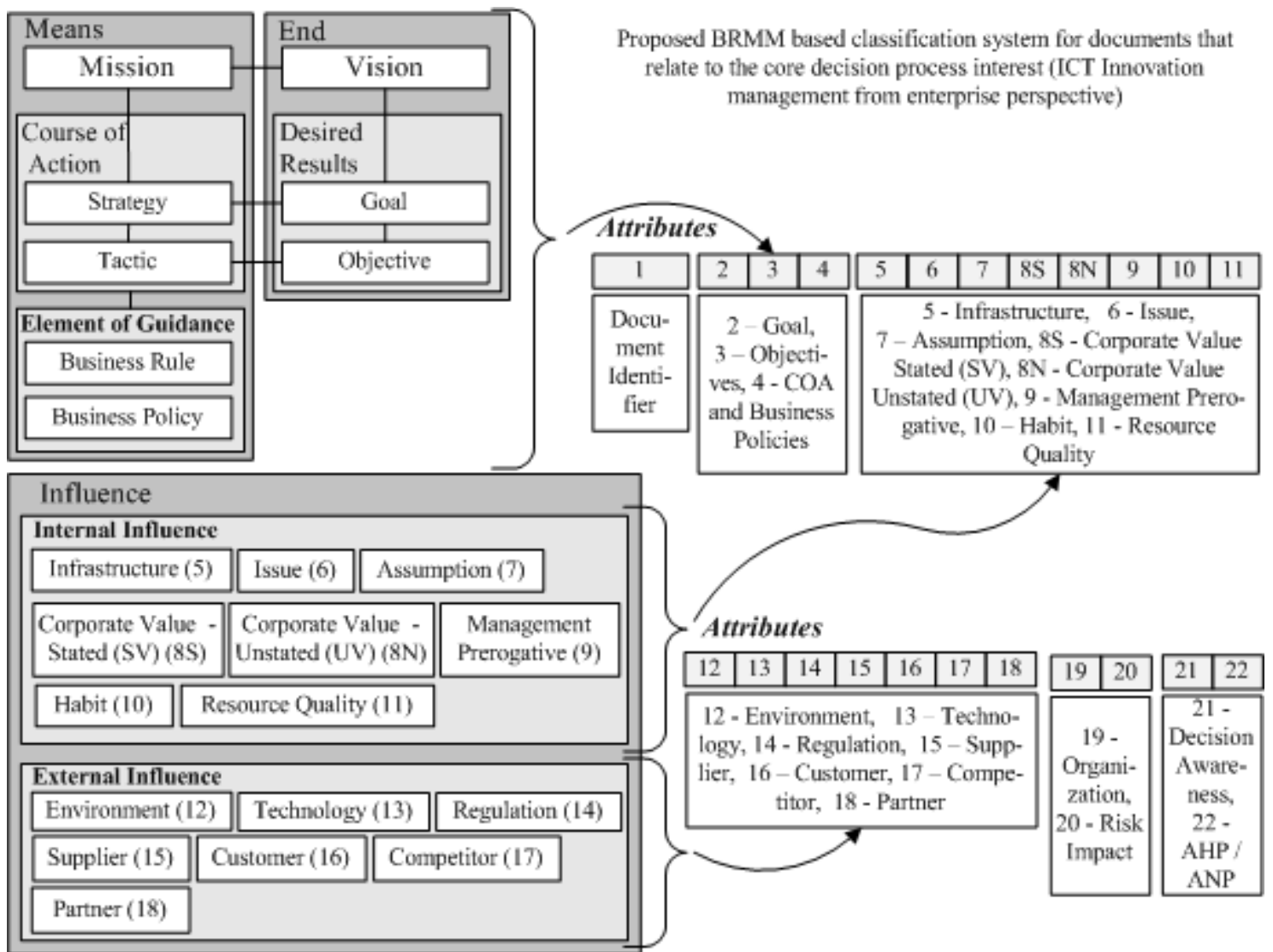

Figure 5. BRMM as a basement for classification system

Classification system in the figure 5 does not pretend to become a "classification standard"; it is primarily a mechanism that allows experienced analyst effectively classify a set of scientific papers from conferences like ISAHP, MCDM, IEEE, SCI, CITSA, PISTA (see a list of resources in the Appendix 1) eventually others with similar topics. A classification mechanism works in three steps:

Step 1: Scanning proceedings and a choice of a candidate set of papers for in depth analysis

Step 2: Selection and reduction of a candidate set and creation of abstract for each paper included in a result set

Step 3: Creating a "document / paper profile using attributes listed in the figure 5.

First two steps seem to be intuitively understandable for everybody who regularly works with scientific information resources like proceedings or journals. We illustrate third step using small example - an Abstract relevant to the identifier IEEE 2004 / 05 (Appendix 1).

Abstract example

1. Bibliographic data: K.H.C.K.Sha, C.Y.Hung, B.S.P. Ling: "Evaluation Development Strategies for Taiwan's iB3G Industry: a Fuzzy MCDM Approach”.

2. Abstract:

Foreseeing an enormous demand for seamless communication and ubiquitous interconnectivity, Taiwan has launched a national-level Dual Network Program called integrated beyond the third generation (iB3G) to seize the opportunities posed by technological discontinuity. The iB3G initiative aims to leverage Taiwan's manufacturing strengths and brand Taiwan as a powerhouse in the creation of integrated cellular/WLAN technologies and services. This paper attempts to secure a consensus on the optimal development strategies and their effective implementation. Our analysis employs a fuzzy Multicriteria Decision Making (FMCDM) framework with an empirical formula to examine its practicability and usefulness. Based on business, technical and environmental issues, strategies are proffered as 
follows: (1) shared-value chain and cross-industry collaboration; (2) attractive applications/rich content and service trials on networks; (3) collaborative $R \& D$ of multimode handsets and integrated network systems; (4) active participation in international standard activities to advance intellectual property; (5) proactive policy tools for business innovation, cultivation of talent and entrepreneurship; (6) supportive regulatory mechanism and sound broadband environment, and (7) promoting the iB3G vision worldwide and asserting leadership. Three clusters are extracted among the seven strategies by Fuzzy C-Means approach. Results show that the second strategy receives the highest score.

To sustain competitive advantages it is essential, for both an enterprise and a country, to anticipate and prepare for future discontinuities in science, technology and business models, and to develop control points quickly by leveraging emerging opportunities that the discontinuities represent [1]. Due to the rapid grassroots growth of wireless local-area network (WLAN), which is seen as a potential platform for $4 G$ (the 4th generation) with advantages including high bandwidth, quick deployment, multimedia services and low cost, it is expected that discontinuities in the telecom industry will occur.

In this research we use Multi-criteria decision-making (MCDM) methods including Analytic Hierarchy Process (AHP) and Fuzzy C-Means (FCM) approaches to establish and evaluate the development strategies.

3. 1 (Document Identifier): IEEE 2004 / 05

4. Classification in accordance with attribues: 2/Y, 3/Y, 4/Y, 11/Y, $13 / \mathrm{Y}, 14 / \mathrm{Y}, 15 / \mathrm{Y}, 16 / \mathrm{Y}, 21 / \mathrm{Y}$, 22/Y.

5. Comment: Paper clearly identifies Goal, Objectives and Course of Action (attributes $2-4$ ), and analysis primarily external influences (from enterprise perspective) - see attributes 13,14,15,and 16. Paper is "decision awareness" and applies AHP.

Appendix 1 includes a list of classified documents and their "BRMM" profiles. These profiles contain high information entropy that would be converted into control hierarchy of criteria. Next section describes basic idea about such conversion.

\section{Example}

Very nice Thomas Saaty's ideas that "Both ordinal ranks and their cardinal priorities can be obtained from paired comparisons" and that "Cognitive psychologists have recognized our inborn ability to use comparative judgment to identify and compare the relative intensity of some relation between two stimuli both present to an observer" [14] are not directly applicable to our BRMM profiles. We do not want to find document with the highest similarity to "our" decision problem. We need all documents to synthesize ANP control hierarchy for a class of decisions that allow enterprises repeatedly use this model for strategic or tactical decisions (see figure 4). In this case we need to transform all entropy captured in BRMM profiles into hierarchical network model supported by Super-Decision software [11].

Our transformation considers particular steps recommended by Rozann [11]:

- Determine the most general network of clusters (or components) and their elements that apply to all the control criteria.

- For each control criterion or subcriterion, determine the clusters of the general feedback system with their elements and connect them according to their outer and inner dependence influences. An arrow is drawn from a cluster to any cluster whose elements influence it

- Determine the approach you want to follow in the analysis of each cluster or element, influencing (the preferred approach) other clusters and elements with respect to a criterion, or being influenced by other clusters and elements. The sense (being influenced or influencing) must apply to all the criteria for the four control hierarchies for the entire decision.

Our starting position supposes that the most general network of clusters correspond to five groups of attributes identified in the figure 5 (Attributes $\{2,3,4)$ - Cluster 1 , Attributes $(5,6, . .11)$ - Cluster 2, Attributes $(12,13, . .18)$ - Cluster 3, Attributes $(19,20)$ - Cluster 4 and finally Attributes 21,22) - Cluster 5).

With respect of a cluster border we can account correlation among attributes as a number of documents that include any characteristic combination of values (in our case a pair of values $\{\mathrm{Y}, \mathrm{Y}\}$ ). 
All correlations are described in table 1. The first level of splitting corresponds to clusters 1 to 5 (relationships among these clusters remember ANP super matrix).

Each cluster includes a set of attributes (this assignment was made in the figure 5). White cells include inter-relationships among attributes within particular cluster. Red cells include intra-relationships among attributes in different clusters. Violet cells do not include any value - super matrix is symmetric.

Table 2 can be understood as a compromised matrix because it describes only influences of attributes to external clusters.

\begin{tabular}{|c|c|c|c|c|c|c|c|c|c|c|c|c|c|c|c|c|c|c|}
\hline & \multicolumn{3}{|c|}{ Cluster 1} & \multicolumn{7}{|c|}{ Cluster 2} & \multicolumn{7}{|c|}{ Cluster 3} \\
\hline & & 2 & 3 & 4 & 5 & 6 & 7 & 8 & 9 & 10 & 11 & 12 & 13 & 14 & 15 & 16 & 17 & 18 \\
\hline & 2 & & 0,703 & 0,649 & 0,216 & 0,081 & 0,162 & 0,378 & 0,297 & 0,162 & 0,297 & 0,405 & 0,622 & 0,297 & 0,405 & 0,297 & 0,162 & 0,162 \\
\hline-1 & 3 & & & 0,541 & 0,189 & & 0,108 & 0,243 & 0,189 & 0,108 & 0,216 & 0,270 & 0,514 & 0,216 & 0,351 & 0,243 & 0,108 & 0,135 \\
\hline$\dot{0}$ & 4 & & & & 0,189 & 0,081 & 0,135 & 0,216 & 0,243 & 0,081 & 0,189 & 0,297 & 0,459 & 0,216 & 0,324 & 0,189 & 0,108 & 0,108 \\
\hline & 5 & & & & & & & & 0,081 & & & 0,108 & 0,162 & & 0,135 & 0,081 & & \\
\hline & 6 & & & & & & & & & & & & 0,081 & & & & & \\
\hline & 7 & & & & & & & 0,108 & 0,081 & & 0,081 & 0,135 & 0,135 & & & & & \\
\hline & 8 & & & & & & & & 0,243 & 0,081 & 0,216 & 0,135 & 0,189 & 0,108 & 0,108 & 0,081 & & 0,108 \\
\hline$\cong$ & 9 & & & & & & & & & & 0,162 & 0,162 & 0,162 & 0,081 & 0,108 & 0,081 & & 0,108 \\
\hline$\frac{\bar{\Phi}}{\omega}$ & 10 & & & & & & & & & & 0,081 & 0,135 & 0,108 & 0,135 & 0,081 & & & 0,081 \\
\hline 인 & 11 & & & & & & & & & & & 0,162 & 0,216 & 0,162 & 0,162 & 0,108 & & 0,108 \\
\hline & 12 & & & & & & & & & & & & 0,324 & 0,216 & 0,270 & 0,216 & 0,162 & 0,162 \\
\hline & 13 & & & & & & & & & & & & & \begin{tabular}{|l|}
0,189 \\
\end{tabular} & 0,351 & 0,243 & 0,162 & 0,162 \\
\hline & 14 & & & & & & & & & & & & & & 0,189 & 0,135 & 0,081 & 0,108 \\
\hline & 15 & & & & & & & & & & & & & & & 0,243 & 0,162 & 0,135 \\
\hline$m$ & 16 & & & & & & & & & & & & & & & & 0,135 & 0,108 \\
\hline$\stackrel{\Phi}{0}$ & 17 & & & & & & & & & & & & & & & & & 0,081 \\
\hline & 18 & & & & & & & & & & & & & & & & & \\
\hline
\end{tabular}

Table 1.

\begin{tabular}{|c|c|c|c|c|c|c|c|c|c|c|c|c|c|c|c|c|c|}
\hline & \multicolumn{3}{|c|}{ Cluster 1} & \multicolumn{7}{|c|}{ Cluster 2} & \multicolumn{7}{|c|}{ Cluster 3} \\
\hline & 2 & 3 & 4 & 5 & 6 & 7 & 8 & 9 & 10 & 11 & 12 & 13 & 14 & 15 & 16 & 17 & 18 \\
\hline Cluster 1 & & & & 0,198 & 0,081 & 0,135 & 0,279 & 0,243 & 0,117 & 0,234 & 0,324 & 0,532 & 0,243 & 0,360 & 0,243 & 0,126 & 0,135 \\
\hline Cluster 2 & 0,228 & 0,176 & 0,162 & & & & & & & & 0,140 & 0,151 & 0,122 & 0,119 & 0,088 & & 0,101 \\
\hline Cluster 3 & 0,336 & 0,263 & 0,243 & 0,122 & 0,081 & 0,135 & 0,122 & 0,117 & 0,108 & 0,153 & & & & & & & \\
\hline
\end{tabular}

Table 2.

\section{Conclusion}

ICT innovation is a big challenge for enterprise managers offering them to win or loss in a competitive business environment. Many ICT innovations are too complex to be easily analyzed from BOCR perspective for a particular enterprise. We describe new approach how to overcome this problem.

BOCR model is powerful if it does already exist for a decision maker problem. If such model does not exist (it is the case of ICT Innovation) the most time and resource consuming is a synthesis of a decision context. We propose application of Zachman architecture framework for context capturing. Using this framework we can dive into decision support model known as BRMM. We propose BOCR enhancement that allows decision makers:

- integration of BOCR models with more broader decision contexts captured within Zachman Architecture Framework

- merging BRMM items with decision elements used in ANP hierarchical control networks

Proposed approach allows synchronization of Dynamic ANP model with <AS-IS, NEXT-STEP, SHOULD BE $>$ life cycle applied by enterprises for strategic and tactical decisions.

Last possibility how to simplify ANP hierarchical control networks synthesis deals with a classification of information resources in accordance with BRMM compatible profiles and their following transformation into ANP network topology. 
Directions for further research include:

- $\quad$ Finishing an ANP model synthesized on the BRMM platform and checking sensitivity of the final ICT driven model

- $\quad$ Elaboration with decision context captured by the Zachman framework.

\section{References}

[1] ISAHP 2003: Proceedings of the Sevens International Symposium on the Analytic Hierarchy Process, August 2003, Nusa Dua, Bali - Indonesia.

[2] MCDM 2004: Proceedings of the $17^{\text {th }}$ International Conference Multiple Criteria Decision Making, Simon Fraser University, August, 2004, Whistler, Canada.

[3] SCI 2004: Proceedings of the $8^{\text {th }}$ World Multiple-Conference on Systemic, Cybernetics and Informatics, July 2004, Orlando, Florida, USA.

[4] Andreichicov,A.V., Anreichicova,O.N.: “The Analysis of The Technical Systems' Evaluation”, [1], pp. $121-126$.

[5] Feglar,T.: "AHP/ANP Usage for a Cooperation between IT Architect and Decision Maker”, [2]

[6] French,S., Xu,D.L.: “Comparison Study of Multi-Attribute Decision Analytic Software”, [2]

[7] Karpak,B,., Bayazit,O.: "Prioritizing Enterprise Resource Planning Software: An AHP Approach”, [2]

[8] Levy,J.K., Feglar,T., Taji,K.: ”A Framework For Critical Infrastructure Security: Using Analytic Hierarchy Process for Radioactive Waste Managemnent:, [2]

[9] Lo,M.Ch., Chang,Ch.Y., Tzeng,G.H.: "Effect Evaluation on Enforcing Information Quality of Knowledge Management”, [2]

[10] Polancic,G., Horvat,R.V.: "A Model for Comparative Assessment of Open Source Products", [3]

[11] Saaty,Rozann.W.: "Decision Making in Complex Environment", Super Decisions Software for Decision Making with Dependency and Feedback.

[12] Saaty,T.L.: "The Analytic Network Process - Decision Making With Dependence and Feedback", RWS Publications, Pittsburgh, ISBN 0-9620317-9-8.

[13] Saaty,T.L.:”Time Dependent Decision - Making: Dynamic Priorities in AHP / ANP”, [1] / pp. 1 38.

[14] Saaty, T.L., Mujgan O.: "Priority as Dominance in Derived Measurement: Invariance of the Principal Eigenvector”, ISAHP 2003 CD.

[15] The Business Rules Group: “Organizing Business Plans - The Standard Model for Business Rules Motivation”, November 15, 2000, 47 p., http://www.BRCommunity.com 


\begin{tabular}{|c|c|c|c|c|c|c|c|c|c|c|c|c|c|c|c|c|c|c|c|c|c|c|}
\hline \multicolumn{23}{|c|}{ APPENDIX 1: BRMM Profiles characterizing classified documents } \\
\hline 1 & 2 & 3 & 4 & 5 & 6 & 7 & 8 & 9 & 10 & 11 & 12 & 13 & 14 & 15 & 1 & \begin{tabular}{l|l}
6 & 1 \\
\end{tabular} & 7 & 18 & 19 & 20 & 21 & 22 \\
\hline SCI $2004 / 01$ & $\mathrm{Y}$ & $\mathrm{Y}$ & $\mathrm{Y}$ & & & & SV & $\mathrm{Y}$ & & $\mathrm{Y}$ & & & $\mathrm{Y}$ & & & & & & $\mathrm{Y}$ & & $\mathrm{Y}$ & $\mathrm{N}$ \\
\hline SCI 2004 / 02 & $\mathrm{Y}$ & $\mathrm{Y}$ & $\mathrm{Y}$ & & & & & & & & $\mathrm{Y}$ & $Y$ & & $Y$ & & & & & & & $\mathrm{Y}$ & $Y$ \\
\hline SCI $2004 / 03$ & $\mathrm{Y}$ & & $\mathrm{Y}$ & & $\mathrm{Y}$ & $\mathrm{Y}$ & SV & $\mathrm{Y}$ & & & & $Y$ & & & & & & & & & $\mathrm{Y}$ & $\mathrm{N}$ \\
\hline $\mathrm{SCl} 2004 / 04$ & $\mathrm{Y}$ & & & & & $\mathrm{Y}$ & SV & & & $Y$ & $\mathrm{Y}$ & $Y$ & & & & & & & & & $\mathrm{Y}$ & $\mathrm{N}$ \\
\hline $\mathrm{SCl} 2004 / 05$ & $\mathrm{Y}$ & & & $\mathrm{Y}$ & & & SV & $\mathrm{Y}$ & & $\mathrm{Y}$ & & & & & & & & & & $\mathrm{Y}$ & $\mathrm{N}$ & $\mathrm{N}$ \\
\hline \multicolumn{23}{|l|}{$\mathrm{SCl} 2004 / 06$} \\
\hline CITSA 2004 / 01 & $\mathrm{Y}$ & $\mathrm{Y}$ & $\mathrm{Y}$ & $\mathrm{Y}$ & & & & & & & & $Y$ & & $\bar{Y}$ & & & & & & & $\mathrm{~N}$ & $\mathrm{~N}$ \\
\hline CITSA 2004 / 02 & $\mathrm{Y}$ & & & & & & $\mathrm{Y}$ & $\mathrm{Y}$ & & & & & & & & & & & & & $\mathrm{Y}$ & $\mathrm{N}$ \\
\hline CITSA 2004 / 03 & $\mathrm{Y}$ & $\mathrm{Y}$ & $\mathrm{Y}$ & & $\mathrm{Y}$ & & & & & & & $Y$ & & & & & & & $\mathrm{Y}$ & & $\mathrm{N}$ & $\mathrm{N}$ \\
\hline PISTA 2004 / 01 & $\mathrm{Y}$ & $\mathrm{Y}$ & $\mathrm{Y}$ & & & & & & & & & $\mathrm{Y}$ & $\mathrm{Y}$ & $Y$ & & & & & $\mathrm{Y}$ & & $\mathrm{N}$ & $\mathrm{N}$ \\
\hline PISTA $2004 / 02$ & $\mathrm{Y}$ & $\mathrm{Y}$ & $\mathrm{Y}$ & & & & & & & & & $\mathrm{Y}$ & & & 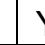 & 1 & & & & & $\mathrm{~N}$ & $\mathrm{~N}$ \\
\hline PISTA 2004 / 03 & $\mathrm{Y}$ & $\mathrm{Y}$ & $\mathrm{Y}$ & & & & & & & & & $Y$ & & & & & & & & & $\mathrm{~N}$ & $\mathrm{~N}$ \\
\hline PISTA 2004 / 04 & $\mathrm{Y}$ & $Y$ & $\mathrm{Y}$ & $\mathrm{Y}$ & & & & & & & & $Y$ & & & & & & & $\mathrm{Y}$ & & $\mathrm{N}$ & $\mathrm{N}$ \\
\hline PISTA 2004 / 05 & $\mathrm{Y}$ & $\mathrm{Y}$ & $\mathrm{Y}$ & & $Y$ & $\mathrm{Y}$ & SV & $\mathrm{Y}$ & $\mathrm{Y}$ & $\mathrm{Y}$ & $\mathrm{Y}$ & $Y$ & $Y$ & $\bar{Y}$ & & & & $\mathrm{Y}$ & $\mathrm{Y}$ & $\mathrm{Y}$ & $\mathrm{N}$ & $\mathrm{N}$ \\
\hline 1 & 2 & 3 & 4 & 5 & 6 & 7 & 8 & 9 & 10 & 11 & 12 & 13 & 14 & 15 & & \begin{tabular}{l|l}
6 & 1 \\
\end{tabular} & $17:$ & 18 & 19 & 20 & 21 & 22 \\
\hline IEEE 2004 / 01 & $\mathrm{Y}$ & $Y$ & & & & & & & $Y$ & & & $Y$ & & & & & & & $\mathrm{Y}$ & & $\mathrm{N}$ & $N$ \\
\hline IEEE 2004 / 02 & $\mathrm{Y}$ & $\mathrm{Y}$ & $\mathrm{Y}$ & & & & & & & & & & & & & & & & & & $\mathrm{Y}$ & $Y$ \\
\hline IEEE 2004 / 03 & $\mathrm{Y}$ & $Y$ & $\mathrm{Y}$ & & & $\mathrm{Y}$ & & & & $\mathrm{Y}$ & $Y$ & $Y$ & $\mathrm{Y}$ & $Y$ & ( & 1 & $Y$ & & & & $\mathrm{Y}$ & $Y$ \\
\hline IEEE 2004 / 04 & $\mathrm{Y}$ & & & & & & SV & & $Y$ & $\mathrm{Y}$ & $\mathrm{Y}$ & $Y$ & $Y$ & $Y$ & & 1 & $Y$ & $Y$ & $\mathrm{Y}$ & & $\mathrm{Y}$ & $N$ \\
\hline IEEE 2004 / 05 & $\mathrm{Y}$ & & $\mathrm{Y}$ & & & & & & & $\mathrm{Y}$ & & $Y$ & $Y$ & $Y$ & 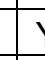 & 1 & & & & & $\mathrm{Y}$ & $Y$ \\
\hline IEEE 2004 / 06 & $\mathrm{Y}$ & & $\mathrm{Y}$ & & & & & $\mathrm{Y}$ & & & $\mathrm{Y}$ & $Y$ & & $\bar{Y}$ & ) & 1 & $Y$ & & $\mathrm{Y}$ & & $\mathrm{N}$ & $\mathrm{N}$ \\
\hline IEEE 2004 / 07 & $\mathrm{Y}$ & $\mathrm{Y}$ & $\mathrm{Y}$ & & & & UV & $\mathrm{Y}$ & & $\mathrm{Y}$ & $\mathrm{Y}$ & $Y$ & & $\bar{Y}$ & -1 & 1 & & $Y$ & & & $\mathrm{~N}$ & $\mathrm{~N}$ \\
\hline IEEE 2004 / & $\mathrm{Y}$ & $Y$ & $\mathrm{Y}$ & & & & UV & $\mathrm{Y}$ & $Y$ & $Y$ & $\mathrm{Y}$ & $Y$ & $\mathrm{Y}$ & & & & & $\mathrm{Y}$ & & $\mathrm{Y}$ & $\mathrm{N}$ & $\mathrm{N}$ \\
\hline IEEE 2004 / 09 & & & & & & & & & & & & $\bar{Y}$ & & & & & & & $\mathrm{Y}$ & & & \\
\hline IEEE 2004 / 11 & & & $\mathrm{Y}$ & $\mathrm{Y}$ & & $\mathrm{Y}$ & & $\mathrm{Y}$ & & & $\mathrm{Y}$ & & & & & & & & $\mathrm{Y}$ & & & \\
\hline 1 & 2 & 3 & 4 & 5 & 6 & 7 & 8 & 9 & 10 & 11 & 12 & 13 & 14 & 15 & 51 & $\begin{array}{ll}6 & 1\end{array}$ & 17 & 18 & 19 & 20 & 21 & 22 \\
\hline SCIJ 01 & $\mathrm{Y}$ & & $\mathrm{Y}$ & & & & & & & & $\mathrm{Y}$ & & $Y$ & & & & & & & & $\mathrm{~N}$ & $N$ \\
\hline \multirow[t]{2}{*}{ SCIJ 02} & $\mathrm{Y}$ & $\mathrm{Y}$ & & $\mathrm{Y}$ & & $\mathrm{Y}$ & & & & & $\mathrm{Y}$ & $Y$ & & & ( & , & & & & & & \\
\hline & & & & & & & & & & & & & & & & & & & & & $\mathrm{N}$ & $\mathrm{N}$ \\
\hline SCIJ 03 & $\mathrm{Y}$ & & $\mathrm{Y}$ & & & & & & $\mathrm{Y}$ & & $\mathrm{Y}$ & & $\mathrm{Y}$ & & & & & & & & & \\
\hline SClJ 04 & $\mathrm{Y}$ & $\mathrm{Y}$ & & & & & & & $\mathrm{Y}$ & & $\mathrm{Y}$ & & $Y$ & $\bar{Y}$ & ( & & & & & & $\mathrm{N}$ & $\mathrm{N}$ \\
\hline SCIJ 05 & $\mathrm{Y}$ & $\mathrm{Y}$ & & & & & & & & & $\mathrm{Y}$ & $Y$ & $Y$ & $Y$ & 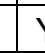 & ' & Y & $Y$ & & & $\mathrm{~N}$ & $N$ \\
\hline ISAHP2003 / 01 & $\mathrm{Y}$ & $Y$ & & & & & $\mathrm{Y}$ & $\mathrm{Y}$ & & $\mathrm{Y}$ & & & & & & & & & & & $\mathrm{Y}$ & $Y$ \\
\hline ISAHP2003 / 03 & $\mathrm{Y}$ & $Y$ & & & & & $\mathrm{Y}$ & & & & & $Y$ & & & & & & & & & $\mathrm{Y}$ & $\mathrm{Y}$ \\
\hline 1 & 2 & 3 & 4 & 5 & 6 & 7 & 8 & 9 & 10 & 11 & 12 & 13 & 14 & 15 & 51 & 6 & 17 & 18 & 19 & 20 & 21 & 22 \\
\hline S $278 \times Q . p d f$ & $\mathrm{Y}$ & $\mathrm{Y}$ & $\mathrm{Y}$ & $\mathrm{Y}$ & & & & & & $\mathrm{Y}$ & & $Y$ & & $\mathrm{Y}$ & & & & & & $\mathrm{Y}$ & $\mathrm{N}$ & $Y$ \\
\hline 16 KM.pdf & $\mathrm{Y}$ & $Y$ & $\mathrm{Y}$ & $\mathrm{Y}$ & & & & & & & $\mathrm{Y}$ & $\bar{Y}$ & & $\bar{Y}$ & & & $\bar{Y}$ & & & $\mathrm{Y}$ & $\mathrm{N}$ & $Y$ \\
\hline R 395 YQ.pdf & $\mathrm{Y}$ & $\mathrm{Y}$ & $\mathrm{Y}$ & $\mathrm{Y}$ & & & & $\mathrm{Y}$ & & & $\mathrm{Y}$ & $\mathrm{Y}$ & & $\mathrm{Y}$ & 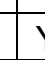 & ' & Y & $\mathrm{Y}$ & & $\mathrm{Y}$ & $\mathrm{N}$ & $Y$ \\
\hline R 837 GD.pdf & $\mathrm{Y}$ & $Y$ & $\mathrm{Y}$ & & & $\mathrm{Y}$ & $\mathrm{Y}$ & & & & & & & & & & & & & $\mathrm{Y}$ & $\mathrm{N}$ & $Y$ \\
\hline S 054 EF:pdf & $\mathrm{Y}$ & $\mathrm{Y}$ & $\mathrm{Y}$ & $\mathrm{Y}$ & & & $\mathrm{Y}$ & & & & & & & $\bar{Y}$ & ( & & & & & $\mathrm{Y}$ & $\mathrm{N}$ & $\mathrm{Y}$ \\
\hline S 607 YE.pdf & $\mathrm{Y}$ & $\mathrm{Y}$ & $\mathrm{Y}$ & & & & $Y$ & $\mathrm{Y}$ & & & & & & & & & & & & $\mathrm{Y}$ & $\mathrm{N}$ & $\mathrm{Y}$ \\
\hline
\end{tabular}

SV = Corporate value - Stated

$U V=$ Corporate value Unstated 


\section{APPENDIX 1: List of Documents Used for BRMM Classification}

1. CITSA 2004, International Conference on Cybernetics and Information Technologies, Systems and Applications, July 21-25, 2004, Orlando, Florida, USA.

2. SCI'2005, The 8th World Multi-Conference on Systemics, Cybernetics and Informatics, Proceedings. July 18-21, 2004 Orlando, Florida, USA.

3. IEEE 2004, International Engineering Management Conference, 18-21 October 2004, SINGAPORE

4. PISTA 2004, International Conference on Politics and Information Systems: Technologies and Applications, July 2004, Orlando, Florida, USA.

5. SCIJ: Journal of Systemic, Cybernetics and Informatics.

6. ISAHP 2003, Proceedings of the Sevens International Symposium on the Analytic Hierarchy Process, August 2003, Nusa Dua, Bali - Indonesia.

7. SCI2004/01: IS Failure: Just too Much Information? Kieren JAMIESON and and Paul HYLAND [2]

8. SCI2004/02: Research on Simulation Based Communication Network Design Technology and Support Environment, Wei SU, Xueshan LUO, Yaohong ZHANG, Dhenglong XIU [2]

9. SCI2004/03: A Meta-synthetic decision Support System for complex problem solving. Xiang-lan HAN, Hui-zhong WU, Sheng-lei CHEN, Yao-qin ZHU [2]

10. SCI2004/04: The use of Economic Intelligence process and information and communication technologies to enhance decision process in an enterprise. Chedia DHAOUI, Amos DAVID [2]

11. SCI2004/05: Representing Subjective Knowledge in Engineering Systems Using Possibility Trees. Sunil Donald, Terry F. Bott, and Stephen W. Eisenhawer [2]

12. SCI2004/06: Six sigma real-time decision making management system for integrating production, design and development, marketing and finance management in Taiwan, Tzann-Dwo Wu [2]

13. CITSA 2004/01: Introduction of Ubiquitous Networking project "Ubila" - Present status of Ubiquitous national project in Japan, Masayoshi Ohashi, Takafumi Hamai, Thitomi Murakami, Tohru Asami, Tomonori Aoyama; Yoshiaki Kiriha, Yuji Oie, [1]

14. CITSA 2004/02: A Fuzzy MADM Approach for the Implementation of a BSC-Based Performance Evaluation System, Fu, Chung-Jen (Taiwan); Shih, Chih-Yuan [1]

15. CITSA 2004/03: RETIS - A Framework to Analyse the Requirements Engineering Tendency of Information Systems, Rocha, Álvaro; Braga de Vasconcelos, José [1]

16. PISTA 2004/01: Enhancing the E-Governance Model: Enterprise Architecture as a Potential Methodology to Build a Holistic Framework, Zwahr, Thomas and Finger, Matthias [1]

17. PISTA 2004/02: E-Government Information Quality (e-GIQ) Framework, Chutimaskul, Wichian; Wangpipatwong, Sivaporn (Thailand), [4].

18. PISTA 2004/03: e-Participation Model in Thailand, Chutimaskul, Wichian and Funilkul, Suree [4]

19. PISTA 2004/04: 21st Century Governance as a Complex Adaptive System, Hartzog, Paul B. [4]

20. PISTA 2004/05: Networking Technologies and the Rate of Technological Change, Mitchell, Charles L. [4]

21. IEEE 2004/01: The Seven Habits of Highly Effective Programs, Practices you need to change your organization with information technology, Mark Crowne, [3]

22. IEEE 2004/02: The Rise of Systems Engineering within the Australian Defence Organisation, S. C. Cook, [3]

23. IEEE 2004/03: How Incremental Innovation Becomes Disruptive: The Case of Technology Convergence 32, F. Hacklin, V. Raurich, C. Marxt, [3]

24. IEEE 2004/04: TRIZ-aided Technology Mapping for Information System Implementation 239, J. W. K. Chan, K. M. Yu, [3]

25. IEEE 2004/05: Evaluating Development Strategies for Taiwans iB3G Industry: a Fuzzy MCDM Approach 258, K. H. C. K. Sha, C. Y. Hung, B. S. P. Lin, [3]

26. IEEE 2004/06: New Direction and Strategy of MOT Practice in Just-in-Time Innovation, A. Kameoka, M. Li, [3]

27. IEEE 2004/07: Reasons for Road mapping: A Study of the Singaporean SME Manufacturing Sector 292, C. J. Holmes, M. B. A. Ferrill, R. Phaal, [3]

28. IEEE 2004/08: Management of Technological Changes and Innovations as a Core Competence 407, G. A. Sazonova, A. N. Kolishchak, [3]

29. IEEE 2004/09: Architectural Capacity for Attaining Innovation 422, N. Taji, [3] 
30. IEEE 2004/11: Framework for Innovation in Business Practice Unit, Sato, Kunagai, Tsukuda,Numata [3]

31. SCIJ 01 (2): The most significant ICT Policies influence

32. SCIJ 02 (2): Maximize a benefit of a Broadband Network

33. SCIJ 03 (2): The highest Internet Penetration in Rate

34. SCIJ 04 (2): Optimal Strategy for e-government innovation

35. SCIJ 05 (2): The most probable way in which the Internet will improve democracy in China

36. ISAHP2003 / 01: To be an excellent company in Engineering and Construction Industry in South East Asia

37. ISAHP2003 / 03: To relevant the most perspective vibro protective for protection 